PRINCIPLES OF ENGINEERING THERMODYNAMICS 
Other titles of related interest

G. Boxer, Applications of Engineering Thermodynamics

G. Boxer, Engineering Thermodynamics

E. M. Goodger, Combustion Calculations

E. M. Goodger, Hydrocarbon Fuels

P. Polak, Theory and Practice in Engineering Thermodynamics

J. R. Simonson, Computing Methods in Solar Heating Design 


\title{
Principles of Engineering Thermodynamics
}

\author{
E. M. GOODGER
}

Senior Lecturer, School of Mechanical Engineering, Cranfield Institute of Technology, Bedford and Sometime Professor of Mechanical

Engineering, The University of Newcastle, N.S.W., Australia

Second Edition

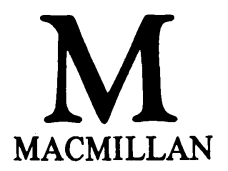


(C) E. M. Goodger 1974, 1984

All rights reserved. No part of this

publication may be reproduced or transmitted, in any form or by any means, without permission.

First edition 1974

Reprinted 1982

Second edition 1984

Published by

Higher and Further Education Division

MACMILLAN PUBLISHERS LTD

London and Basingstoke

Companies and representatives

throughout the world

ISBN 978-0-333-37150-3 ISBN 978-1-349-86025-8 (eBook)

DOI 10.1007/978-1-349-86025-8 
'Thermodynamics is a funny subject. The first time you go through it, you don't understand it at all. The second time you go through it, you think you understand it, except for one or two small points. The third time you go through it, you know you don't understand it, but by that time you are so used to it, it doesn't bother you any more.'

Attributed to Arnold Sommerfeld with acknowledgement to S. W. Angrist and L. G. Hepler. Order and Chaos! Basic Books, London and New York (1967). 


\section{Contents}

Preface to First Edition $\quad x i$

Preface to Second Edition xiii

Units $x v$

Physical Constants $x i x$

$\begin{array}{ll}\text { Notation } & x x\end{array}$

1 Basic Concepts 1

1.1 Thermodynamic Systems 2

1.2 Thermodynamic Properties and State 3

1.3 Two-Property Rule 5

1.4 Thermodynamic Processes 6

Test Questions - Chapter 1

2 Energy 10

$\begin{array}{ll}2.1 \text { Energy Forms } & 10\end{array}$

2.2 Empirical Temperature 11

2.3 Energy Transfer 13

2.3.1 Work transfer 15

2.3.2 Heat transfer 19

Test Questions - Chapter $2 \quad 21$

3 Energy Conversion 23

3.1 First Law of Thermodynamics 23

3.2 Energy Equations 24

3.3 Energy Distribution in Non-Flow Processes 28

3.4 Energy Distribution in Steady-Flow Processes 31

3.5 Second Law of Thermodynamics 33

3.6 Thermal Efficiency 34

3.7 The Carnot Cycle 39 
3.8 Thermodynamic Temperature

Test Questions - Chapter 3

Problems - Chapter 3

$4 \quad$ Entropy

4.1 The Entropy Concept 46

4.2 Third Law of Thermodynamics 52

4.3 Availability, or Exergy 53

4.4 Free Energy 61

4.5 Thermodynamic Relationships 66

$\begin{array}{ll}\text { Test Questions - Chapter } 4 & 70\end{array}$

$\begin{array}{ll}\text { Problems - Chapter } 4 & 70\end{array}$

5 Ideal Gases and Mixtures $\quad 72$

5.1 Equation of State for Ideal Gas 72

5.2 Temperature Relationships in Ideal Gas 75

$\begin{array}{lll}5.3 & \text { Specific Heat Capacities } & 78\end{array}$

5.4 Perfect Gas 80

5.5 Energy Distribution in Non-Flow Processes 83

5.5.1 The general polytropic non-flow process $\quad 84$

5.5.2 The isentropic non-flow process 84

5.5.3 The isothermal non-flow process 85

5.5.4 The isobaric non-flow process $\quad 85$

5.5.5 The isochoric non-flow process 86

5.6 Energy Distribution in Steady-Flow Processes 87

5.6.1 The polytropic steady-flow process (no effects of motion, gravity, etc.)

5.6.2 The isentropic steady-flow process (no effects of motion, gravity, etc.) 88

5.6.3 The isothermal steady-flow process (no effects of motion, gravity, etc.)

5.6.4 The isobaric steady-flow process (no effects of motion, gravity, etc.) 88

5.6.5 The isochoric steady-flow process (no effects of motion, gravity, etc.) 89

5.6.6 The isentropic non-work steady-flow process (finite
effect of motion, no effects of gravity, etc.)

5.7 Entropy Changes in Processes 90

5.8 Mixtures of Ideal Gases 91

5.9 Liquid-Vapour Mixtures 94

5.10 Steam 95

5.11 Hygrometry, or Humidity, or Psychrometry 100

$\begin{array}{ll}\text { Test Questions - Chapter } 5 & 106\end{array}$

$\begin{array}{ll}\text { Problems - Chapter 5 } & 107\end{array}$ 
6 Thermodynamic Process Applications 109

6.1 Ideal Processes as Performance Criteria 109

6.2 Positive Displacement Compression and Expansion Processes 109

6.2.1 Positive displacement compression 110

6.2.2 Positive displacement expansion 117

6.3 Ducted-Flow Compression and Expansion Processes 120

6.3.1 Fixed duct compression and expansion 120

6.3.2 Rotary duct compression and expansion 122

6.3.2.1 Rotary duct compression $\quad 126$

6.3.2.2 Rotary duct expansion 131

6.4 Heat Release Processes 138

6.5 Heat Exchange Processes 144

Test Questions - Chapter $6 \quad 148$

$\begin{array}{ll}\text { Problems - Chapter } 6 & 149\end{array}$

$7 \quad$ Thermodynamic Cycle Applications $\quad 151$

7.1 Ideal Cycles as Performance Criteria 151

7.2 The Stirling, Otto and Diesel Gas Power Cycles 154

7.2.1 Positive displacement heat engines 158

$\begin{array}{ll}7.3 \text { The Joule Gas Power Cycle } & 167\end{array}$

7.3.1 Cycle analysis of the representative gas turbine plant 173

7.4 The Rankine Vapour Power Cycle 176

7.4.1 The regenerative (unsuperheated) cycle 184

7.4.2 Economiser and air-preheater systems 186

$\begin{array}{ll}\text { 7.4.3 Secondary heat transfer } & 186\end{array}$

7.4.4 Binary Rankine cycle $\quad 186$

7.4.5 Combined cycles 187

7.5 Refrigerator and Heat Pump Cycles 190

Test Questions - Chapter 7 196

Problems - Chapter $7 \quad 196$

$\begin{array}{lr}\text { Summary } & 199\end{array}$

$\begin{array}{lr}\text { Conclusions } & 205\end{array}$

$\begin{array}{ll}\text { References and Bibliography } & 209\end{array}$

$\begin{array}{lr}\text { Solutions to Test Questions } & 210\end{array}$

Methods and Solutions to Problems 215

Additional Problems with Solutions $\quad 222$

$\begin{array}{ll}\text { Glossary } & 224\end{array}$ 
Appendix A: Thermodynamic Expressions for Reversible Processes

Index 


\section{Preface to First Edition}

The emergence of mankind from the primitive world has been marked, and indeed made possible, by an increasing familiarity with the many forms of energy that exist in nature. In England for example the useful conversion of chemical energy to mechanical energy through the medium of heat was one of the cornerstones of the Industrial Revolution some two centuries ago, but the steam engines of those early days were mainly practical achievements developed by intuition and rule-of-thumb, with little insight into the principles involved. Steadily however theory caught up with, and eventually directed, the design of heat-work devices of all kinds, and the subject of thermodynamics is now firmly established as one of the most general theories of physical science, with ramifications far beyond the fields of energy transfer and conversion.

The teaching of thermodynamics has undergone corresponding developments, particularly in recent years. Formerly, each application of the subject was presented separately with its related packet of theory, and very often in chronological order of development, but nowadays emphasis is placed on the fundamental concepts in order to show the broad relationships, rather than the differences, between the many applications. Again, it was customary-and in some teaching schemes the tendency persists-for the physical nature of thermodynamic fluids to be presented first, and subsequently the thermodynamic laws themselves. In the present work, however, thermodynamic considerations of energy forms, energy transfer and energy conversion are dealt with in the first half of the book, and only then are the physical properties of fluids introduced. The thermodynamic behaviour of these fluids can be appreciated with greater ease following the initial grounding in the nature of energy. Applications to heat and work processes and cycles in practice are then arranged in an order that is systematic, with no restrictions of chronology. In this way, an integrated view of the subject is presented, with fundamentals and applications in proper perspective.

Many textbooks exist in the field of thermodynamics, with differing degrees of breadth and depth of treatment. The prime objective of the present work is to identify and explain the main principles on which the subject is based, and to present them in as concise a form as possible without losing essential detail. 
This approach can be helpful both to the learner, who may otherwise become lost in a wealth of information, and to those seeking rapid revision.

The material is presented in the conventional chapter-and-section format, with related worked examples, test questions and problems. At appropriate points in the text the reader is referred back to derivations in earlier sections. In some cases applications or further developments of given concepts are foreshadowed by reference to later sections, but these need not be followed up in a first reading since their greatest value lies in tying together the various aspects of the subject during revision.

Being concerned directly with principles, the book lends itself to most syllabuses on the subject, up to and including first-degree level. However, such topics as entropy, availability and free energy do not figure largely in the more elementary types of examination syllabus, and in these cases may be studied in less detail. Other topics, such as gas analysis for air-fuel ratio determination, are not included since they are more properly handled elsewhere, for example, in books on fuels and combustion. Since a broad experience in problem solving is recommended, attention is drawn to several textbooks where further examples may be found.

Acknowledgement is made gratefully to colleagues and students of the University of Newcastle, N.S.W., and the Cranfield Institute of Technology, Milton Keynes, for much valued assistance in the form of discussion and feedback, and particularly to Professor A. H. Lefebvre, Head of the School of Mechanical Engineering, Cranfield, for the facilities made available to enable this work to be prepared. 


\section{Preface to Second Edition}

The aims of this second edition are to provide a systematic, consistent and concise treatment of engineering thermodynamics in a manner suited to both initial learning and revision, as before, and also to incorporate the experience gained from the first edition. It seeks therefore to identify and clarify the major aspects of the subject, and to arrange them into a pattern that develops the argument in a logical manner without the complication of the many fascinating side issues. These are available in the larger textbooks, and can be mastered more easily by subsequent study.

The energy foundation on which this book is built consists of concentrating first on energy forms, transfers and conversions before proceeding to the behaviour of idealised fluids and their applications to practical processes and cyclic devices and plant. Particular care has been taken over the mathematical sign convention used, which is a common source of confusion. Some approaches define the signs to suit the argument in hand but, in this book, the standard thermodynamic convention has been explained carefully and then used consistently, hence the reader can refer to any section in the certain knowledge of the meaning of each sign.

The material contained in the first edition has been in continuing use as a basis for lectures at Cranfield and elsewhere, and has generated valuable feedback both on matters of detail from successive groups of students, and on the wider issues from the reviewers, all of which is greatly appreciated. One review criticism raised, quite rightly, was that in some areas the book was brief rather than concise. This oversight arose because the areas concerned are customarily dealt with thoroughly in parallel lectures, and so are covered elsewhcre for the student following a formal course. For the general reader, however, such superficial treatment is quite unhelpful, consequently this present edition is more balanced, with the needs of both undergraduate student and general reader firmly in mind. In particular, greater coverage is given to such topics as units, exergy, hygrometry, rotary compressors and expanders, heat exchange, cycle analysis and combined-cycle plant.

The energy approach adopted here has attracted some interest, including a suggestion that this aspect be developed further at the expense of the comprehensive analyses of the various thermodynamic processes. This suggestion is not 
accepted, however, since such a philosophical exercise seems more suited to subsequent study.

The opportunity has been taken to make several improvements in clarity and accuracy, including the correction of one or two mis-statements that had escaped detection. It is hoped that this second offering will have cause to earn itself a place amongst the considerable literature on the subject, that its systematic energy-based presentation will help many who find difficulty with this very fundamental subject, and that suggestions for further improvement will continue to be forthcoming.

In preparing this revision, acknowledgement is made gratefully to Professor R. S. Fletcher, academic colleagues and students of the Cranfield School of Mechanical Engineering, and to the SME Drawing Office for its continuing excellence in preparing the illustrations.

Cranfield, 1984

E. M. Goodger 


\section{Units}

In any system of units, a number of quantities are defined as fundamental to the system, and all the remaining quantities derived from them. If the system is coherent, the products and quotients of any two or more unit quantities themselves become the units of the derived quantities, in the absence of any conversion factors or proportionality constants. The rationalised system of metric units known as SI (Systeme International d'Unités) is coherent in this way, and applies to all branches of science and engineering.

The quantities and units of interest in this study consist of the following.

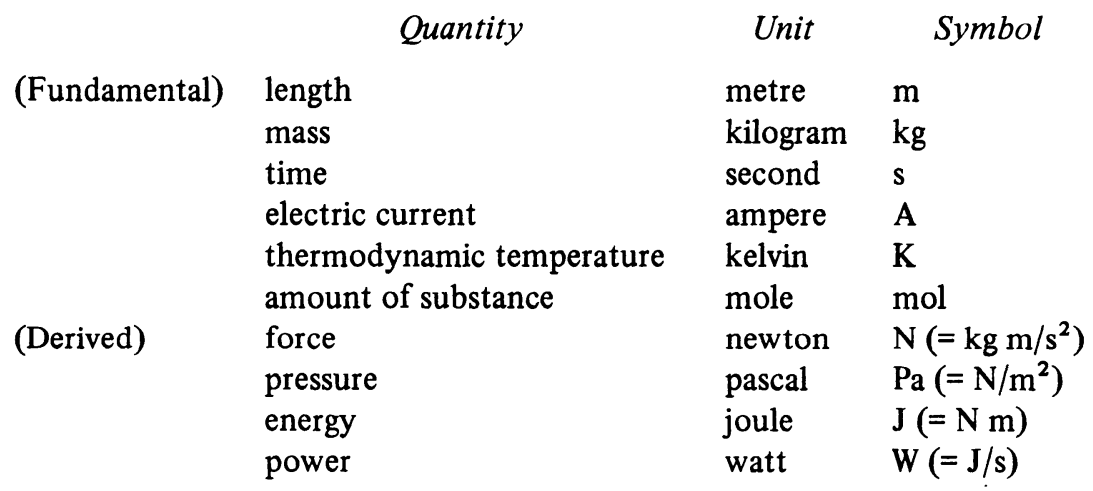

The kelvin is also applied to temperature intervals. The mole relates to what was formerly called the 'gram-mole' and not to the 'kilogram-mole (kmol)'.

No change is made to any symbol to indicate the plural, and quantities are generally expressed in units that result in numerical values between 0.1 and 1000; preferred single multiples and submultiples differ in stages of 10 raised to a power that is a multiple of \pm 3 , ranging normally from $10^{18}$, exa, to $10^{-18}$, atto.

SI has been adopted by many industries, some of which also use earlier metric units (litre, bar, centipoise, centistokes) together with non-metric units (atmosphere) which are considered acceptable. Since the adoption of SI is not yet worldwide, the following conversion factors and other metric relationships are given. 


\begin{tabular}{|c|c|}
\hline Length & $\begin{array}{l}1 \mathrm{in}=25.4 \mathrm{~mm} \\
1 \mathrm{ft}=0.3048 \mathrm{~m} \\
1 \mathrm{mile}=1.609 \mathrm{~km}\end{array}$ \\
\hline \multirow[t]{3}{*}{ Volume } & $1 \mathrm{ft}^{3}=0.02832 \mathrm{~m}^{3}$ \\
\hline & $1 \mathrm{UKgal}=1.201 \mathrm{USgal}=4.5461$ \\
\hline & $1 \mathrm{US} \mathrm{gal}=0.8327 \mathrm{UKgal}=3.7851$ \\
\hline \multirow[t]{4}{*}{ Mass } & $1 \mathrm{lb}=0.4536 \mathrm{~kg}$ \\
\hline & 1 (long) ton $=2240 \mathrm{lb}=1016 \mathrm{~kg}$ \\
\hline & 1 short ton $=2000 \mathrm{lb}=907.6 \mathrm{~kg}$ \\
\hline & 1 tonne $=0.9842$ (long) ton $=1000 \mathrm{~kg}=1 \mathrm{Mg}$ \\
\hline Density & $1 \mathrm{lb} / \mathrm{ft}^{3}=16.02 \mathrm{~kg} / \mathrm{m}^{3}$ \\
\hline Force & $1 \mathrm{lbf}=4.448 \mathrm{~N}$ \\
\hline \multirow[t]{4}{*}{ Pressure } & $1 \mathrm{lbf} / \mathrm{in}^{2}=6.895 \mathrm{~Pa}$ \\
\hline & $1 \mathrm{~mm} \mathrm{Hg}=133.3 \mathrm{~Pa}$ \\
\hline & $1 \mathrm{~atm}=1.01325 \mathrm{bar}=101325 \mathrm{kPa}$ \\
\hline & $1 \mathrm{bar}=100 \mathrm{kPa}=10^{5} \mathrm{~Pa}$ \\
\hline \multirow[t]{7}{*}{ Energy } & $1 \mathrm{Btu}=1.055 \mathrm{~kJ}$ \\
\hline & $1 \mathrm{Chu}=1.899 \mathrm{~kJ}$ \\
\hline & $1 \mathrm{kcal}($ international table) $=4.1868 \mathrm{~kJ}$ \\
\hline & $1 \mathrm{kcal}($ thermochemical $)=4.184 \mathrm{~kJ}$ \\
\hline & $1 \mathrm{kWh}=3.6 \mathrm{MJ}$ \\
\hline & $1 \mathrm{hph}=2.685 \mathrm{MJ}$ \\
\hline & 1 therm $=10^{5} \mathrm{Btu}=105.5 \mathrm{MJ}$ \\
\hline \multirow[t]{2}{*}{ Specific energy } & $1 \mathrm{Btu} / \mathrm{lb}=2.326 \mathrm{~kJ} / \mathrm{kg}$ \\
\hline & $1 \mathrm{Chu} / \mathrm{lb}=4.1868 \mathrm{~kJ} / \mathrm{kg}$ \\
\hline Specific energy capacity & $1 \mathrm{Btu} / \mathrm{lb}{ }^{\circ} \mathrm{R}=1 \mathrm{Chu} / \mathrm{lb} \mathrm{K}=4.1868 \mathrm{~kJ} / \mathrm{kg} \mathrm{K}$ \\
\hline \multirow[t]{3}{*}{ Energy density } & $1 \mathrm{Btu} / \mathrm{ft}^{3}=0.03726 \mathrm{~kJ} / 1\left(\right.$ or $\left.\mathrm{MJ} / \mathrm{m}^{3}\right)$ \\
\hline & $1 \mathrm{Chu} / \mathrm{ft}^{3}=0.06707 \mathrm{~kJ} / 1\left(\right.$ or $\left.\mathrm{MJ} / \mathrm{m}^{3}\right)$ \\
\hline & $1 \mathrm{Btu} / \mathrm{UKgal}=0.2321 \mathrm{~kJ} / 1$ (or $\left.\mathrm{MJ} / \mathrm{m}^{3}\right)$ \\
\hline Power & $1 \mathrm{hp}=745.7 \mathrm{~W}$ \\
\hline \multirow[t]{3}{*}{ Temperature } & $\mathrm{K}={ }^{\circ} \mathrm{C}+273.15$ \\
\hline & ${ }^{\circ} \mathrm{F}=(9 / 5)^{\circ} \mathrm{C}+32$ \\
\hline & ${ }^{\circ} \mathrm{R}={ }^{\circ} \mathrm{F}+459.67$ \\
\hline
\end{tabular}

(Figures in bold type are exact)

The current SI has developed from earlier systems based on gravitational units and on technical units. The confusion that sometimes arises over the use of units in engineering is generally due not so much to these unit systems themselves, but because the same metric-type units can appear in more than one system, and because the earlier systems still have their devotees. An overall understanding of relevant units is important in any subject, but the following attempt at disentanglement is limited to all that is necessary in the present context.

From Newton's Law of Gravitation, two bodies of masses $m$ and $m^{\prime}$, with their centres displaced by a distance $r$, exert between their centres attractive forces on each other of magnitude $F$ given by 


$$
F=k_{\mathrm{G}} \frac{m m^{\prime}}{r^{2}}
$$

where $k_{\mathrm{G}}$ is a universal gravity constant equal to $6.6732 \times 10^{-11} \mathrm{~N} \mathrm{~m}^{2} / \mathrm{kg}^{2}$.

In most everyday applications of gravity, the major body is the Earth which has a mass $m^{\prime}$ of approximately $5.98 \times 10^{24} \mathrm{~kg}$ and radius $r$ of approximately $6.37 \times 10^{6} \mathrm{~m}$. The gravitational weight force $F_{\mathrm{w}}$ exerted per unit mass of a relatively small body of mass $m$ located on the surface of the Earth is given by

$$
\begin{aligned}
\frac{F_{\mathrm{w}}}{m} & =k_{\mathrm{G}} \frac{m^{\prime}}{r^{2}} \\
& =9.80665 \mathrm{~N} / \mathrm{kg}
\end{aligned}
$$

where this value applies to the Earth only and is not a universal constant.

This expression was then related to Newton's Second Law of Motion, given by

$$
\begin{aligned}
F & \propto m a \\
& =\left(1 / g_{c}\right) m a
\end{aligned}
$$

where $g_{c}$ can be described as a universal motion constant equal to $1 \mathrm{~kg} \mathrm{~m} / \mathrm{N} \mathrm{s}^{2}$, and $a$ is the acceleration resulting from the action of the force on the mass. Comparison of (1) and (2) then indicates why, under the action of gravity at the surface of the Earth, a body falling freely in a vacuum is found to experience an acceleration given by

$$
a=9.80665 \mathrm{~m} / \mathrm{s}^{2}
$$

The importance of terrestrial gravity to Earth-bound observers is such that a special symbol, $g$, has been adopted for this constant acceleration, where $g$ applies to the Earth only and is not a universal constant. (On the surface of the Moon, for example, the corresponding value of gravitational acceleration is only 0.16 of the terrestrial value. It follows, nevertheless, that a force of $1 \mathrm{~N}$ applied in any direction to a body of mass $1 \mathrm{~kg}$ will produce an acceleration of 9.80665 $\mathrm{m} / \mathrm{s}^{2}$ in the direction of the applied force, and that this value is a universal constant for such conditions.)

The gravitational weight force per unit mass in equation (1) can now be written as

$$
\begin{aligned}
\frac{F_{\mathrm{w}}}{m} & =\frac{g}{g_{\mathrm{c}}} \\
& =\frac{9.80665}{1} \frac{\mathrm{m} / \mathrm{s}^{2}}{\mathrm{~kg} \mathrm{~m} / \mathrm{N} \mathrm{s}^{2}}
\end{aligned}
$$

It was then argued that, since $g_{c}$ is unity in a coherent system of units such as SI, this term can be omitted in writing the above equation for Newton's Second Law of Motion on the understanding that it is incorporated by implication, thus 


$$
F=m g, \text { with the } \frac{1}{g_{\mathrm{c}}} \text { omitted but implied }
$$

However, the essence of a coherent system is that the products and quotients of any two or more unit quantities are themselves the units of the derived quantities, in the absence of any constants of proportionality. Consequently, in SI, the expressions

$$
F(\mathrm{~N})=m(\mathrm{~kg}) a\left(\mathrm{~m} / \mathrm{s}^{2}\right) \quad \text { generally }
$$

and

$$
F_{\mathrm{w}}(\mathrm{N})=m(\mathrm{~kg}) g\left(\mathrm{~m} / \mathrm{s}^{2}\right) \quad \text { specifically }
$$

may be written directly with no need for constants or explanations of their invisible presence.

Expressions for potential and kinetic energies now follow by simple application of equations (3) and (4). If the surface of the Earth is adopted as the zero datum for potential energy, a body of mass $m$ at height $z$ above the Earth's surface (where $z$ is small in relation to $r$ so that $F_{\mathrm{w}} / m$ remains nominally constant) possesses a level of potential energy that is equivalent to the work done against its constant gravitational weight force in raising the body through the distance $z$. Thus

$$
\begin{aligned}
\text { Potential energy } & =E_{\mathbf{P}} \\
& =\text { weight force } \times \text { vertical distance moved } \\
& =(m g) z \\
& =9.80665 \mathrm{mz}, \mathrm{J}
\end{aligned}
$$

The level of kinetic energy of a rigid body moving at velocity $C$ relative to a given frame of reference can also be derived from similar reasoning, based on the work done in moving the body from rest, as follows

$$
\begin{aligned}
& \text { Elemental work done }=\text { force } \times \text { elemental distance moved } \\
& \mathrm{d} W=F \mathrm{~d} x \\
& =(m a) \mathrm{d} x \\
& =m \frac{\mathrm{d} C}{\mathrm{~d} t} \mathrm{~d} x \\
& =m \frac{\mathrm{d} x}{\mathrm{~d} t} \mathrm{~d} C \\
& =m C \mathrm{~d} C
\end{aligned}
$$

Thus

$$
\begin{aligned}
\text { Finite work done } & =W=m \int C \mathrm{~d} C \\
& =\text { Kinetic energy }=E_{\mathrm{K}}=m \frac{C^{2}}{2}
\end{aligned}
$$




\section{Physical Constants}

$k_{\mathrm{G}} \quad$ universal gravity constant

$=6.6732 \times 10^{-11} \mathrm{Nm}^{2} / \mathrm{kg}$

$g_{c} \quad$ universal motion constant

$=1 \mathrm{~kg} \mathrm{~m} / \mathrm{N} \mathrm{s}^{2}$

$g \quad$ standard acceleration due to Earth's gravity

$=9.80665 \mathrm{~m} / \mathrm{s}^{2}$

$k_{\mathrm{B}} \quad$ Boltzmann's constant

$=1.3804 \times 10^{-23} \mathrm{~J} /$ molecule $\mathrm{K}$

$N_{0} \quad=$ Avogadro's number

$=6.0247 \times 10^{26}$ molecule $/ \mathrm{kmol}$

$c_{p}$ for air at $1 \mathrm{~atm}$ and $15^{\circ} \mathrm{C}=1.005 \mathrm{~kJ} / \mathrm{kg} \mathrm{K}$

$c_{\nu}$ for air at $1 \mathrm{~atm}$ and $15^{\circ} \mathrm{C}=0.718 \mathrm{~kJ} / \mathrm{kg} \mathrm{K}$

$R$ for air $=0.2867 \mathrm{~kJ} / \mathrm{kg} \mathrm{K}$

$R_{0} \quad$ universal gas constant

$=8.3143 \mathrm{~kJ} / \mathrm{kmol} \mathrm{K}$

$V_{M}$ molar volume of ideal gas

$=22.4136 \mathrm{~m}^{3} / \mathrm{kmol}$ at $1 \mathrm{~atm}$ and $0^{\circ} \mathrm{C}$

$=22.4136 \mathrm{1} / \mathrm{mol} \mathrm{atm}$ and $0^{\circ} \mathrm{C}$

$\sigma \quad$ Stefan-Boltzmann constant

$=56.7 \times 10^{-12} \mathrm{~kW} / \mathrm{m}^{2} \mathrm{~K}^{4}$

Standard atmospheric pressure $=1 \mathrm{~atm}=101325 \mathrm{~Pa}$

Mean value of molar mass of air $=28.9 \mathrm{~g} / \mathrm{mol}$

Ice point of water $=0^{\circ} \mathrm{C}=273.15 \mathrm{~K}$

Triple point of water $=0.01^{\circ} \mathrm{C}=273.16 \mathrm{~K}$ 


\section{Notation}

When two symbols are given for one quantity, upper case represents extensive and lower case specific.

When one symbol is used for more than one quantity, the relevant sections are shown in parentheses.

$\begin{array}{ll}A, a & \text { Non-flow availability function } \\ a & \text { Sonic velocity }(6.3 .1) \\ B, b & \text { Steady-flow availability function } \\ C & \text { Absolute velocity }(2.1,6.3) \\ C & \text { Heat capacity, molar basis }(5.3) \\ c & \text { Specific heat capacity, mass basis } \\ c & \text { Clearance ratio }(6.2 .1) \\ E, e & \text { Energy of a system } \\ E_{\mathrm{K}}, e_{\mathrm{K}} & \text { Kinetic energy } \\ E_{\mathrm{P}}, e_{\mathrm{P}} & \text { Potential energy } \\ F, f & \text { Helmholtz free energy function } \\ G, g & \text { Gibbs free energy function } \\ g & \text { Standard acceleration due to Earth's gravity } \\ g_{\mathrm{c}} & \text { Universal motion constant } \\ H, h & \text { Enthalpy } \\ I, i & \text { Irreversibility } \\ M & \text { Molar mass } \\ m & \text { Mass } \\ N & \text { Number of cycles per minute } \\ n & \text { Number of moles (5.1) } \\ n & \text { Polytropic index (5.5) } \\ p & \text { Pressure } \\ p & \text { Probability (4.1) } \\ Q, q & \text { Heat transfer } \\ R & \text { Gas constant } \\ R_{0} & \text { Universal gas constant } \\ r & \text { Ratio } \\ S, s & \text { Entropy } \\ & \end{array}$




$\begin{array}{ll}T & \text { Absolute, or thermodynamic, temperature, kelvin } \\ t & \text { Empirical temperature, }{ }^{\circ} \mathrm{C} \\ U, u & \text { Internal energy } \\ U & \text { Tangential velocity of rotor (6.3) } \\ V, v & \text { Volume } \\ V & \text { Relative velocity (6.3) } \\ W, w & \text { Work transfer } \\ w & \text { Specific humidity }(5.11) \\ X, x & \text { Exergy } \\ x & \text { Dryness fraction of steam } \\ Y, y & \text { Anergy } \\ z & \text { Height above Earth's surface } \\ \alpha & \text { Angular rotation }(2.3 .1) \\ \alpha & \text { Cut-off ratio in Diesel cycle (7.2) } \\ \beta & \text { Coefficient of performance } \\ \gamma & \text { Specific heat ratio, } c_{p} / c_{v} \\ \epsilon & \text { Electrical potential }(2.3 .1) \\ \epsilon & \text { Effectiveness }(4.3) \\ \eta & \text { Efficiency } \\ \theta & \text { Thermodynamic temperature (3.8) } \\ \theta & \text { Exergetic potential }(4.3) \\ \rho & \text { Density } \\ \sigma & \text { Surface tension } \\ \tau & \text { Torque } \\ \phi & \left.\text { S( } c_{p} / T\right) \text { d } T(5.3) \\ \phi & \text { Relative vapour pressure (5.11) } \\ \omega & \text { Angular velocity }\end{array}$

\section{Superscripts}
0
Standard state of $25^{\circ} \mathrm{C}$ and 1 atmosphere
Internally-based (2.3.1)
Partial $(5.8,5.11)$

\section{Subscripts}

$\begin{array}{ll}\text { A } & \text { Air } \\ \text { a } & \text { axial (6.3.2.1) } \\ \text { a } & \text { Atomisation (6.4) } \\ \text { B } & \text { Burner } \\ \text { b } & \text { Brake } \\ \text { c } & \text { Clearance } \\ \text { comp } & \text { Compressor } \\ \text { CR } & \text { Critical } \\ \text { d } & \text { Diagram }\end{array}$




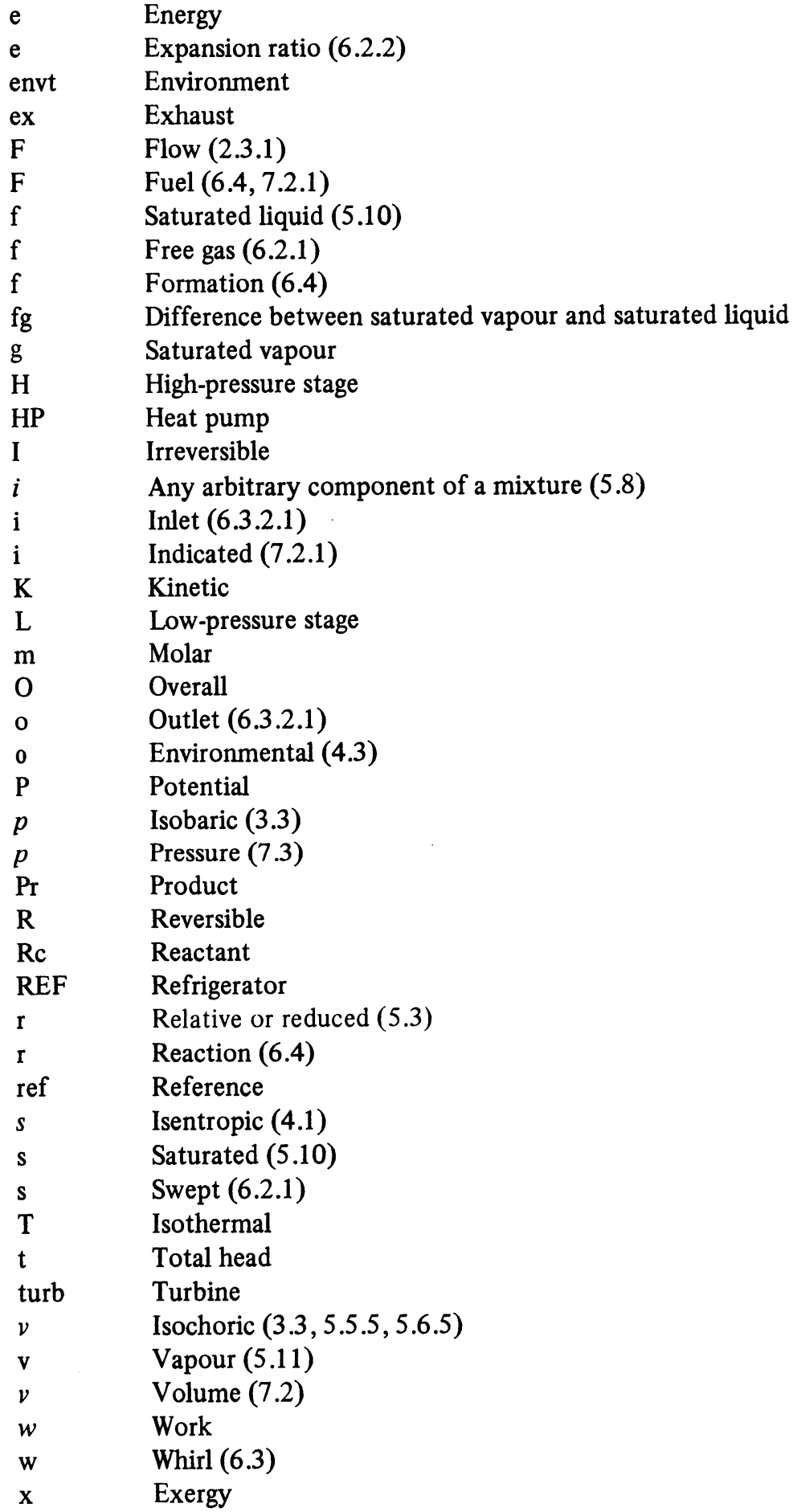

